\title{
Regional Differences of Dental Microwear on the Occlusal Surface of an M2 from Neolithic Japan: A Case Study
}

\author{
Teruyuki Hojo \\ Yahatanisi Mitusada 3-19-5, Kitakyushu City, 807-0805, Japan \\ University of Sangyoidal, School of Medicine, Institute of Anatomy, Anthropology and SEM
}

\begin{abstract}
Regional differences of dental microwear among four small areas on the heavily worn occlusal surface of a mandibular M2 of an adult male from Neolithic Japan were investigated using a scanning electron microscope (SEM). The M2 specimen was cast using a high-resolution epoxy resin under low pressure for SEM, and the cast specimen was sputter-coated with gold. Among the four regions of the M2, two (facets 3 and 9) showed higher proportions of pits $(78.6 \%$ and $75.0 \%$, respectively), and the two others (lingual marginal facet $7 \mathrm{n}$, and the inner side of facet $7 \mathrm{n}$ ) showed lower
\end{abstract}

Macroscopic tooth wear has been investigated with relation to tooth use and diets among numerous different cultures, and various tooth-wear scoring systems have been devised to record the range and pattern of variation (e.g., Bullington, 1991; Hinton, 1981; Molnar 1971; Scott, 1978; Walker, 1978). Such scoring systems depend on overall observations of the occlusal surfaces. But, it also is informative to examine the patterns of tooth wear microscopically because dental microwear reveals that different small regions of a crown are used for processing different foods - and processing food in different ways. Thus, the patterns of microwear differ among various animals corresponding to their diets (Walker et al., 1978). Subsequent to Walker's investigation of microwear of mammalian teeth as an indicator of diet, the assessment of dental microwear on facets has been applied to the study of tooth use and diets of non-human primates and of humans (e.g., Gordon, 1982; Hojo, 1991, 1996; Teaford, 1988; 1994, 1996).

While my previous study reported overall observations on dental microwear of late stone age (Neolithic age) and early modern people (Hojo, 1989), the present study identifies regional difference of dental microwear features on four small occlusal areas of a heavily worn occlusal surface of an $\mathrm{M}_{2}$ of Neolithic Japan using Microwear Image Analyzing Software Version 2.2 3 (Ungar, 1996).

Pits on the heavily worn surfaces of teeth have been found in hard-diet eaters (Hojo, 1991; Teaford, 1994, 1996). In the present study, the high frequency and various sizes of pits on an $M_{2}$ of Neolithic Japan suggest proportions of pits (5.6\% and $33.3 \%$, respectively). The two pitted regions seem to reflect the processing of hard foods, and the two other regions with higher frequencies of striations might reflect exposures to less gritty, softer foods. The variation of these pits and striations suggests that the Jomon subsisted on stone-processed hard foods, with coarse grain sizes of sand in foods that included tuberous roots, animal meats with bones, and clams. The analyses of regional differences of dental microwear will develop important ways to study tooth use and past diets. Dental Anthropology 2005;18(2):61-64.

a variety of hard foods and hard fine sand grains in the foods of Japanese Neolithic people.

Direct evidence of the use of wild vegetables, such as wild yams for grinding, was not found in this Neolithic site, but evidence of wild yams, wild chestnuts and other wild vegetables often are found in Neolithic sites. Also, their foods would become hard through dehydration for preservation. Furthermore, smooth stones and Jōmon style pottery were found in the present archaeological site. Such worked stones could be used for grinding and cutting hard foods (animal meats, bones, and clams), and fragments of pottery may have been used for food processing. The various sizes of pits and striations recorded in this study could be related to the size of grains that were incorporated into foods from stone tools as part of the people's hunter-gathering economy.

\section{MATERIALS AND METHODS}

An $M_{2}$ from Neolithic Japan was of an adult male excavated from the Kakiwara shell mound in western Kyusyu Japan (Matsuno et al., 1967). To avoid damage to the tooth, a high-resolution cast specimen was used. This is because of the risk during the dehydration process or in the specimen chamber of the SEM (scanning electron microscope) that teeth can easily be broken. The high-

Correspondence to: Teruyuki Hojo, Yahatanisi Mitusada 3-19-5, Kitakyushu City, 807-0805, Japan

University of Sangyoidai, School of Medicine, Institute of Anthropology and SEM

E-mail: rhnyb554@yahoo.co.jp 


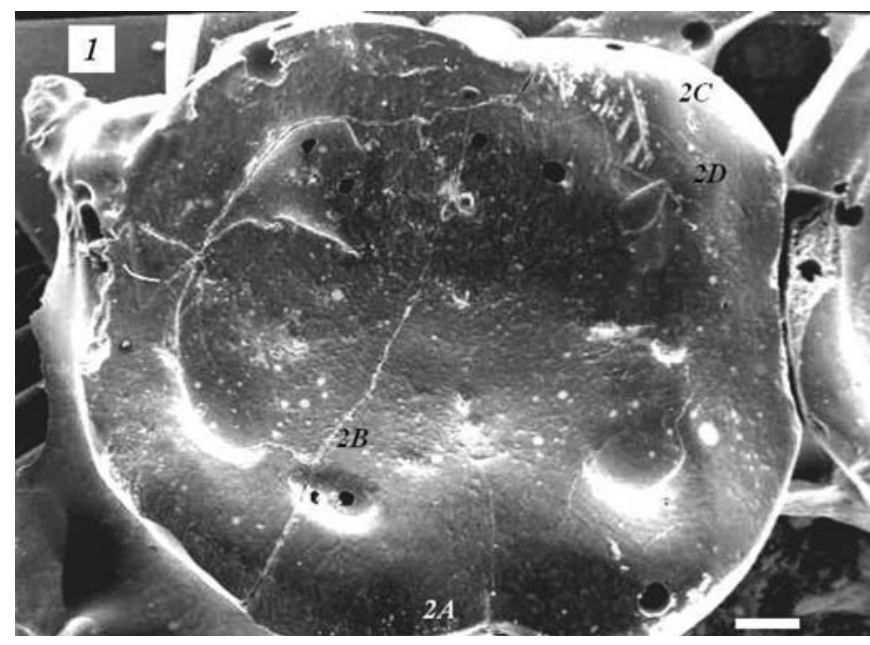

Fig. 1. A heavily worn surface of an $M_{2}$ from Neolithic Japan in overall view using SEM. Four small regions are labeled $(2 \mathrm{~A}, 2 \mathrm{~b}, 2 \mathrm{C}, 2 \mathrm{D})$. The lingual side is up, and the mesial side is right. $\mathrm{Bar}=1,000$ microns.

resolution cast of the $\mathrm{M}_{2}$ was made with a standard technique (e.g., Hojo, 1989, 1991, 1996; Teaford, 1994): First, an impression was taken using a polysiloxane impression material (Coltene, "Light-Body"). Second, a low-viscosity epoxy resin (Ciba-Geigy, "Araldite") was used to make the positive cast. Then, the high-resolution specimen cast was sputter-coated and inspected with an ABT SX-40A SEM (Akashi-Beam Technology, Tokyo Japan) at magnifications ranging from $7 X$ to $500 \mathrm{X}$ at $25 \mathrm{kV}$. The four regions noted in Figure 1 were closely scanned by SEM as follows: the site labeled $2 \mathrm{~A}$ was on facet $3 ; 2 \mathrm{~B}$ was on facet $9 ; 2 C$ was on the lingual marginal facet $7 \mathrm{n}$, and $2 \mathrm{D}$ was on the inner side of facet $7 \mathrm{n}$. Facets 3, 9, and 7n were labeled following Kay (e.g., Kay, 1977; Gordon, 1982). The lengths and widths of pits and striations were measured at the magnification of 500X using Microwear Image Analyzing Software Version 2.2 $\beta$ (Ungar, 1996).

\section{RESULTS AND DISCUSSION}

The macroscopic scoring system of Scott (1979) was applied to the heavily worn occlusal surface of the $M_{2}$ from Neolithic Japan. This specimen was from an adult male, and the attrition score was 8 as can be seen in Figure 1.

Measurements of pits and striations on the four regions of the $\mathrm{M}_{2}$ (Fig. 1) were analyzed through digitization of the wear marks (Ungar, 1996), and the percentages of pits were high in two regions 2A and 2B (Table 1, Fig. 3). Region $2 \mathrm{C}$ showed the highest proportion of striations (94.4\%; Table 1, Fig. 3). Region 2D showed a higher proportion of striations (66.7\%; Table 1, Fig. 3) than regions $2 \mathrm{~A}$ or $2 \mathrm{~B}$. All measurements were computed using a 4:1 ratio of length to width as a cut-off between pits and striations just as suggested by Teaford (1988) and Ungar (1996).

The mean breadth of the pits of the region $2 \mathrm{C}$ was the smallest (Table 1; Fig. 4). As for the mean breadth of the pits, the difference between the region $2 \mathrm{C}$ and $2 \mathrm{D}$ was not statistically significant, but the difference between the region $2 \mathrm{~B}$ and $2 \mathrm{C}$ was highly statistically significant by t-test $(\mathrm{P}<0.001)$, and between regions $2 \mathrm{~B}$ and $2 \mathrm{D}$ also was significant (t-test, $\mathrm{P}<0.001)$.

Two regions (2A and $2 \mathrm{~B}$ ) showed higher proportions of pits $(78.6 \%$ and $75.0 \%$, respectively) and broader pits (17.0 microns and 16.4 microns, respectively). The two other regions (2C and 2D) showed lower proportions of pits (5.6\% and $33.3 \%$, respectively) and smaller pits (6.8 microns and 8.0 microns, respectively).

Because pits are considered to be related to the processing of hard foods (Hojo, 1991; Teaford, 1994, 1996), such numerous and broad pits in the two regions (2A and 2B) suggest that big sand grains might be adhered to the foods in everyday life of the Neolithic age (Figs. 3 and 4). Surprisingly, the highest percentage of pits, $78.6 \%$ in region $2 \mathrm{~A}$, is higher than that of the hard-diet primate, Cercocebus albigena, with $55.2 \%$ pits (Teaford, 1988). And as for mean pit breadths, region 2A

TABLE 1. $\mathrm{M}_{2}$ microwear in Neolithic Japanese (microns)

\begin{tabular}{|c|c|c|c|c|c|c|c|}
\hline & \multicolumn{3}{|c|}{ Striations } & \multicolumn{4}{|c|}{ Pits } \\
\hline & $\mathrm{n}$ & Mean & sd & $\mathrm{n}$ & Mean & $\mathrm{sd}$ & $\%$ of Pits \\
\hline 2A Length & 3 & 75.6 & 15.0 & 11 & 24.2 & 12.8 & 78.6 \\
\hline Breadth & 3 & 3.5 & 1.5 & 11 & 17.0 & 8.0 & \\
\hline 2B Length & 5 & 39.3 & 17.4 & 15 & 28.9 & 13.2 & 75.0 \\
\hline Breadth & 5 & 5.5 & 3.1 & 15 & 16.4 & 8.8 & \\
\hline 2C Length & 51 & 55.6 & 28.8 & 3 & 18.1 & 14.4 & 5.6 \\
\hline Breadth & 51 & 1.9 & 0.9 & 3 & 6.8 & 5.6 & \\
\hline 2D Length & 16 & 40.3 & 18.4 & 8 & 23.3 & 9.9 & 33.3 \\
\hline Breadth & 16 & 5.0 & 1.6 & 8 & 8.0 & 3.0 & \\
\hline
\end{tabular}




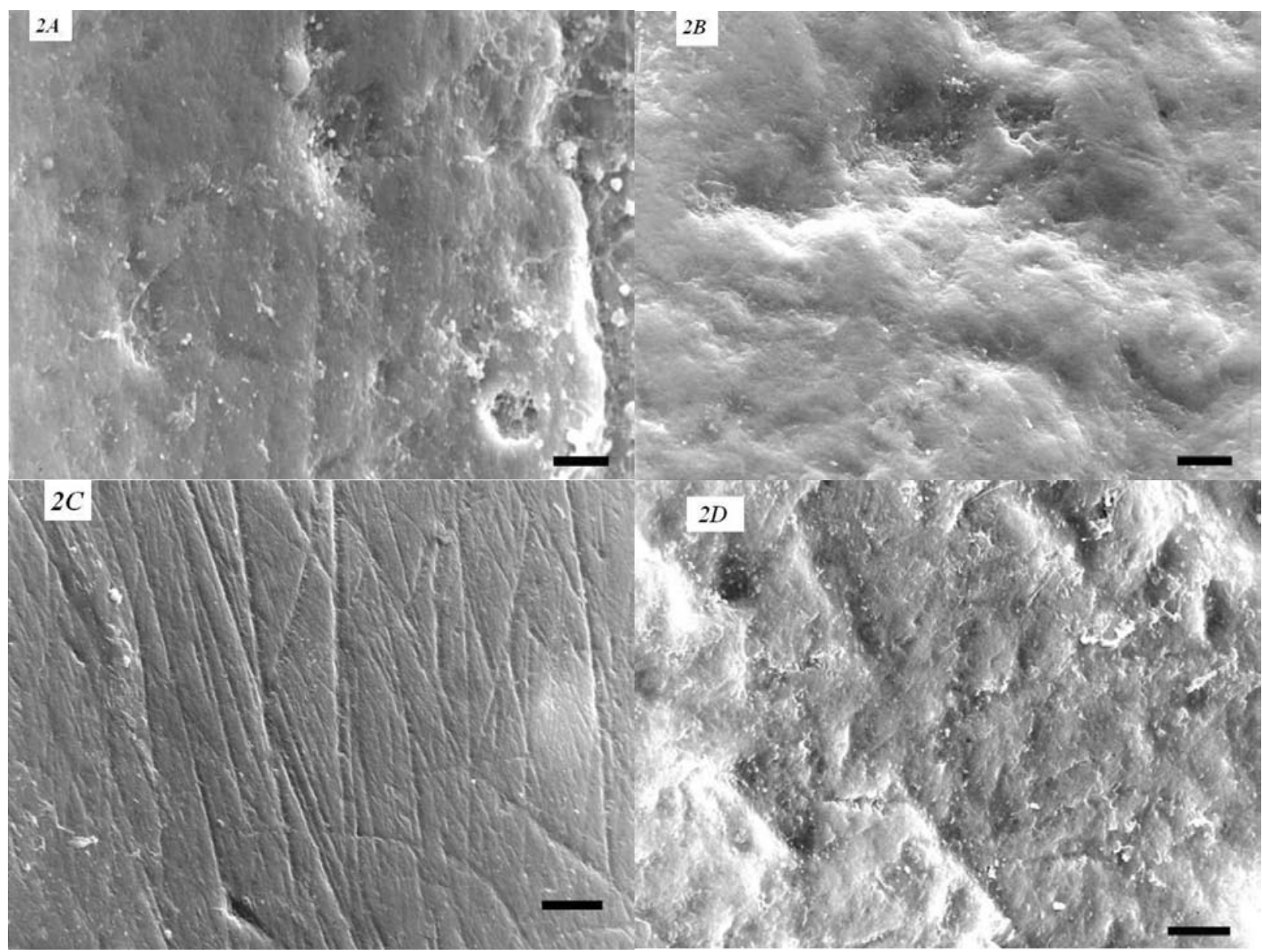

Fig. 2. Figures of four regions (2A, 2B, 2C, and 2D) of SEM that are identified in Figure 1. Pits are preponderant in $2 \mathrm{~A}$, and $2 \mathrm{~B}$, and the broadest pits are seen in $2 \mathrm{~B}$. Many thin striations and a few pits are observed in 2C, and in $2 \mathrm{D}$. Pits in $2 \mathrm{C}$ and in $2 \mathrm{D}$ are less common than those in $2 \mathrm{~A}$ and in $2 \mathrm{~B}$. Bar $=20$ microns.

and $2 \mathrm{~B}$ exhibited mean breadths of 17.0 microns and 16.4 microns, respectively, (Table 1; Fig. 4), but the mean for Cercocebus albigena was just 9.9 microns (Teaford, 1988). This suggests that the two regions (2A and $2 \mathrm{~B})$ of this Neolithic $\mathrm{M}_{2}$ had been abraded by harder and bigger sand grains and substances than the extreme hard-diet primate Cercocebus albigena.

The difference of the mean breadth of striations (Table 1 ) between regions $2 \mathrm{~A}$ and $2 \mathrm{~B}$ was not statistically significant, but the mean breadth of striations of $2 \mathrm{~B}$ was significantly broader than that of $2 \mathrm{C}$ by t-test $(\mathrm{P}<0.001)$. The mean breadth of striations was thinnest in region $2 \mathrm{C}$ (Fig. 4). The image of the region $2 \mathrm{C}$ looks like those of soft-food eaters, Colobus guereza (that has a mean breadth of striations of 1.2 microns; Teaford, 1988). The region $2 \mathrm{C}$ may represent the processing of soft food.

The differences of the lengths of striations (Table 1) among the four regions were statistically insignificant in multivariate analysis.

In brief, measurements of dental microwear for various primate species (Teaford, 1988) suggest that these human four patterns of dental microwear reflect the processing of foods that have incorporated different grain sizes. The grains that abraded the regions $2 \mathrm{C}$ and $2 \mathrm{D}$ are suggested to be smaller than the two others.

Among recent microscopic analyses of tooth wear, there have been interesting experimental studies of dietinduced changes of human tooth wear, for instance, a case of stone-ground maize populations was reported by Teaford (1996). The variation in microwear features in the present study may be related to various kinds of foods. In the environment of this Neolithic human, the foods probably included wild tuberous roots, clams, fish, and animal meat and bones. Even now, in southwestern Japan, both cultivated and wild yams and other wild tuberous roots commonly are eaten. In Japan, stoneground flour has been used widely. Until now, the flour of traditional noodles has been made by stone grinding.

Additionally, in Neolithic Japan (late stone age) some wild vegetables, chestnuts and walnuts were dried for preservation for use out of season, and these would later be stone-ground as were other vegetable roots just as in 


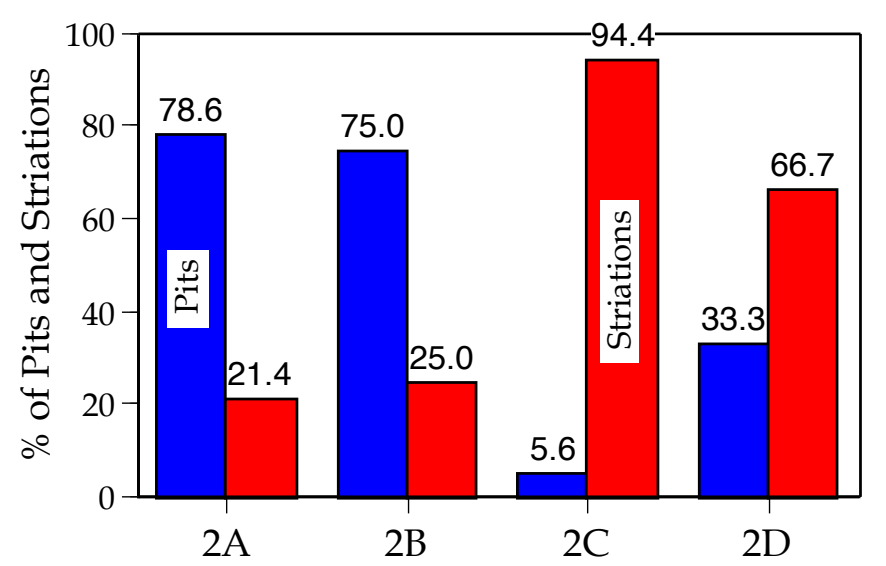

Fig. 3. Frequencies of pits and striations on the four regions of the $\mathrm{M}_{2}$ were analyzed through digitization of the wear marks (Ungar, 1996). Pits of two regions (2A and $2 \mathrm{~B}$ ) showed higher proportions than the two other regions (2C and $2 \mathrm{D})$, which, in turn, showed higher frequencies of striations than the other two regions (2A and $2 \mathrm{~B})$.

modern Japan. Worked stones in this Neolithic site might have been used for grinding and cutting hard foods, and small grains from these stones would be incorporated into the food, just as stone-ground maize was part of the diets of various prehistoric populations (Hinton, 1981). Characteristic changes of dental microwear would be induced by stone-ground maize (Teaford, 1996).

It is anticipated that the further analyses of regional differences of dental microwear will develop important insights into tooth use and prehistoric dietary practices.

\section{LITERATURE CITED}

Bullington J. 1991. Dental microwear of prehistoric juveniles from the lower Illinois River Valley. Am J Phys Anthropol 84:59-73.

Gordon KD. 1982. A study of microwear on chimpanzee molars: Implications for dental microwear analysis. Am J Phys Anthropol 59:195-215.

Hinton RJ. 1981. Form and patterning of anterior tooth wear among aboriginal human groups. Am J Phys Anthropol 54:555-564.

Hojo T. 1989. Dietary differences and microwear on the teeth of Late Stone Age and early modern people from western Japan. Scanning Micros 3:623-628.

Hojo T. 1991. Scanning electron microscopic analyses of dental wear on the heavily worn second molars of the wild Japanese monkeys (Macaca fuscata). Scanning Micros 5:505-508.

Hojo T. 1996. Quantitative analyses of microwear and honing on the sloping crest of the P3 in female Japanese monkeys (Macaca fuscata). Scanning Micros 10;727-736.

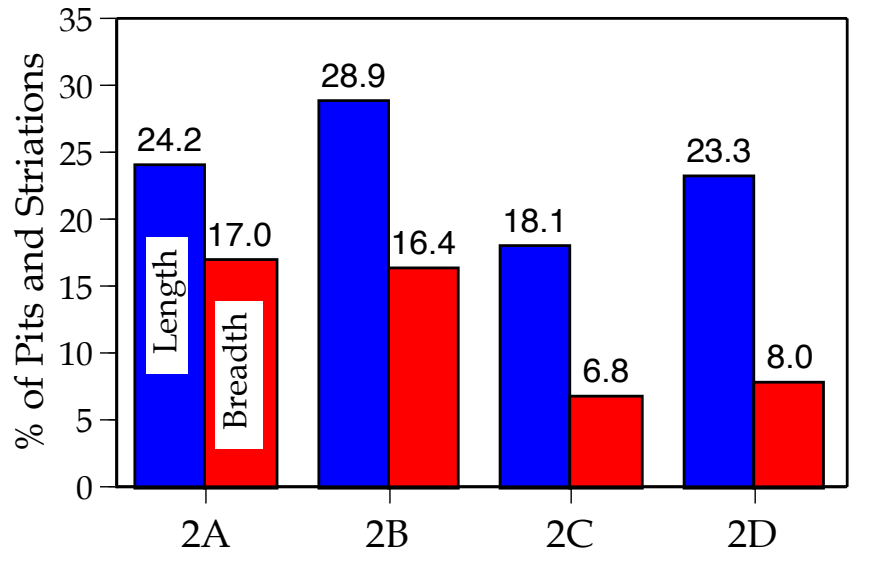

Fig. 4. Measurements of pits and striations on the four regions of the $\mathrm{M}_{2}$ were analyzed through digitization of the wear marks (Ungar, 1996). The mean breadth of the pits of the region $2 \mathrm{C}$ was the most narrow. Pits of two regions (2A and $2 \mathrm{~B}$ ) were broader with higher proportions.

Kay RF. 1977. The evolution of molar occlusion in the Cercopithecidae and early catarrhines. Am J Phys Anthropol 46:327-352.

Matsuno S, Chigoi Y, Nagata T. 1967. On the human skeletons from Kakiwara shell mound in Rokka, Kashima village, Kamimashiki-gun, Higo, Japan. J Kumamoto Med Soc 41:41-52.

Molnar S. 1971. Human tooth wear, tooth function and cultural variability. Am J Phys Anthropol 34;175-190.

Scott EC. 1979. Dental wear scoring technique. Am J Phys Anthropol 51:213-218.

Teaford MF. 1988. A review of dental microwear and diet in modern mammals. Scanning Micros 2:1149-1166.

Teaford MF. 1994. Dental microwear and dental function. In: Evolutionary anthropology, vol. 3. New York: Wiley-Liss, Inc, p 17-30.

Teaford MF. 1996. Brief communication: Diet-induced changes in rates of human tooth microwear: a case study involving stone-ground maize. Am J Phys Anthropol 100:143-147.

Ungar PS. 1996. Microwear image analysis software. Version 2.2 $\beta$. (Version 4.0 now available online at http://pungar@uark.edu/)

Walker A, Hoeck HN, Perez L. 1978. Microwear of mammalian teeth as an indicator of diet. Science 201;908-910.

Walker PL. 1978. A quantitative analysis of dental attrition rates in the Santa Barbara Channel area. Am J Phys Anthropol 48:101-106. 